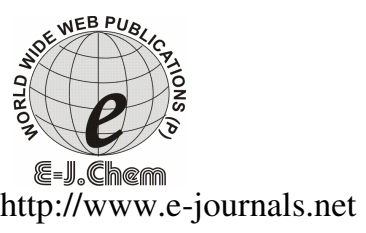

\title{
Chemoselective Preparation of 1,1-Diacetates from Aldehydes, Mediated by a Keggin Heteropolyacid Under Solvent Free Conditions at Room Temperature
}

\author{
G. ROMANELLI*, P. DIMITROFF, P. VÁZQUEZ, and J. C. AUTINO
}

\begin{abstract}
*Centro de Investigación y Desarrollo en Ciencias Aplicadas, Dr. Jorge Ronco (CINDECA), Departamento de Química, Facultad de Ciencias Exactas, Universidad Nacional de La PlataCONICET. Calle 47 Nro 257 (1900) La Plata, Argentina.

"Laboratorio de Estudio de Compuestos Orgánicos (LADECOR), Departamento de Química, Facultad de Ciencias Exactas, Universidad Nacional de La Plata, Calles 47 y 115 (1900) La Plata, Argentina.
\end{abstract}

Received 3 September 2006; Accepted 15 October 2006

\begin{abstract}
A simple, general and efficient method has been developed for the conversion of aldehydes to 1,1-diacetates using acetic anhydride, a catalytic amount of non commercial Keggin heteropolyacid $\left(\mathrm{H}_{6}\right.$ $\left.\mathrm{PAlMo}_{11} \mathrm{O}_{40}\right)(1 \% \mathrm{~mol})$ in solvent free conditions at room temperature. Aromatic and aliphatic, simple and conjugated aldehydes were protected with excellent yields.
\end{abstract}

Keywords: aldehydes, acylals, 1,1-diacetates, solvent-free, heteropolyacid, Keggin catalyst.

\section{Introduction}

Aldehydes are know to react with simple anhydrides to give acylals (1,1-Diacetates) in the presence of acid catalysts. 1,1-Diacetates are synthetically useful for protecting aldehydes owing to their moderate stability in neutral or basic media and their easy formation as well as easy deprotection ${ }^{1}$. The 1,1-Diacetates of $\alpha, \beta$-unsaturated aldehydes are important starting materials for the synthesis of valuable acetoxy dienes and vinyl acetates for DielsAlder cicloaddition reactions ${ }^{2}$. They have also been applied as cross linking reagents for 
cellulose in cotton and useful as activators in the composition of bleaching mixtures used for the treatment of wine-stained fabrics ${ }^{3}$. In addition 1,1-diacetates are useful as substrates in nucleophilic substitution reactions ${ }^{4}$.

1,1-diacetates preparation from aldehydes and acetic anhydride using protonic or Lewis acids as catalysts has been known for a long time. Several catalysts have been employed for this reaction, e.g. sulfuric acid, methanesulfonic, or phosphoric acids ${ }^{5}, \mathrm{FeCl}_{3}{ }^{6} \mathrm{PCl}_{3}{ }^{7}, \mathrm{InCl}_{3}{ }^{8}$ $\mathrm{Sc}(\mathrm{OTf})_{3}{ }^{9}, \mathrm{Cu}(\mathrm{OTf})_{2}{ }^{10}, \mathrm{ZrCl}_{4}{ }^{11}$, among others. However, some of these methods are not entirely satisfactory due to their drawbacks, low yield, long reaction time, environmental problems and tedious work-up.

Several catalysts have been used to improve yields, decrease reaction time and eliminate the unfavorable effects for this reaction, e.g. iodine ${ }^{12}$, expansive graphite ${ }^{13}$, montmorillonite clay $^{14}$, solid superacid as nafion- $\mathrm{H}^{15}$, tungstosilicic acid and $\mathrm{HZSM}-5^{16}$, zirconium sulfophenyl phosphonate ${ }^{17}$, aluminium dodecatungstophosphate ${ }^{18}, \mathrm{LiClO}_{4}{ }^{19}, \mathrm{Zn}\left(\mathrm{ClO}_{4}\right)_{2}{ }^{20}$, 12-molybdophosphoric acid ${ }^{21}, \mathrm{NaHSO}_{4}{ }^{22}$ silica sulfuric $\mathrm{acid}^{23}, \mathrm{KHSO}_{4}{ }^{24}$ and others.

Heteropolycompounds are useful and versatile to a number of transformations because of their redox and superacidic properties. The Keggin primary structure presents the general formula $\left[\mathrm{XM}_{12} \mathrm{O}_{40}\right]^{(8-n)-}$, where $\mathrm{M}$ are addenda atoms, $\mathrm{X}$ is the heteroatom and $n$ is the $\mathrm{X}$ valence. The oxygen atoms in this structure fall into four classes of symmetric-equivalent oxygen: $\mathrm{X}-\mathrm{O}_{\mathrm{a}}-(\mathrm{M})_{3}, \mathrm{M}-\mathrm{O}_{\mathrm{b}}-\mathrm{M}$, connecting two $\mathrm{M}_{3} \mathrm{O}_{13}$ units by corner sharing; $\mathrm{M}-\mathrm{O}_{\mathrm{c}}-\mathrm{M}$, connecting two $\mathrm{M}_{3} \mathrm{O}_{13}$ units by edge sharing and terminal $\mathrm{O}_{\mathrm{d}}-\mathrm{M}$.

We have recently applied heteropolyacids with structure type Keggin for performing the tetrahydropyranylation of phenols and alcohols ${ }^{25}$ and flavones preparation ${ }^{26}$. On the other hand, a heteropolyacid with a type Wells-Dawson structure was used for performing the tetrahydropyranylation-depyranylation of phenols and alcohols ${ }^{27}$, coumarins preparation ${ }^{28}$ and 1,1-diacetates formation and the corresponding deprotection ${ }^{29}$.

As a part of an ongoing research project to develop environmentally friendly organic reactions, we report here a rapid preparation of 1,1-diacetates of aldehydes using a non commercially Keggin heteropolyacids $\left(\mathrm{H}_{6} \mathrm{PAlMo}_{11} \mathrm{O}_{40}\right)$ as catalyst, being tested as a homogeneous catalyst, at room temperature and in solvent free conditions. This Keggin heteropolyacid has been described in a previous paper ${ }^{30}$.

\section{Experimental}

All the products were well previously descript They were characterized by comparison (GLC, TLC, physical constant) with authentic samples prepared by the conventional method, using sulfuric acid as the catalyst as well as ${ }^{1} \mathrm{H}$ and ${ }^{13} \mathrm{C}-\mathrm{NMR}$ All the yields were calculated from crystallized products.

\section{Preparations of the catalyst}

The following procedure was used for the preparation of the molybdenum-substituted heteropolyacid: a stoichiometric mixture of $\mathrm{H}_{3} \mathrm{PO}_{4} 85 \%(0,58 \mathrm{~g}(0,01 \mathrm{~mol})), \mathrm{AlCl}_{3} \cdot 6 \mathrm{H}_{2} \mathrm{O}$ $(1,21 \mathrm{~g}(0,005 \mathrm{~mol}))$ and $\mathrm{MoO}_{3}(14,4 \mathrm{~g}(0,11 \mathrm{~mol}))$ was suspended in $150 \mathrm{ml}$ of distilled water. The mixture was stirred for $6 \mathrm{~h}$ at $80{ }^{\circ} \mathrm{C}$. After cooling down to room temperature and removal of insoluble polymolybdates, the heteropolyacid solution was evaporated and dried at $85{ }^{\circ} \mathrm{C}$ for $24 \mathrm{~h}$. After that, yellow crystals of $\mathrm{H}_{6} \mathrm{PAlMo}_{11} \mathrm{O}_{40}$ were obtained FT-IR: The spectrum of bulk $\mathrm{H}_{6} \mathrm{PMo}_{11} \mathrm{AlO}_{40}$ showed bands at 1064 (P-Oa), 962 (Mo=Od), 869 (Mo-ObMo), 787 (Mo-Oc-Mo), 378 and 342 (bending) cm-1. 


\section{General procedure}

A mixture of an aldehyde 1 ( $1 \mathrm{mmol})$, acetic anhydride $(1 \mathrm{ml})$ and $\mathrm{H}_{6} \mathrm{PAlMo}_{11} \mathrm{O}_{40}(1 \%$ $\mathrm{mmol})$ was stirred at room temperature for $3 \mathrm{~h}$ and then ethyl ether $(10 \mathrm{ml})$ was added to the reaction mixture. The resulting solution was successively washed with $1 \mathrm{M} \mathrm{NaOH}$ and water, dried over anhydrous $\mathrm{Na}_{2} \mathrm{SO}_{4}$ and filtered. The solution was then concentrated, and when the product was solid, was recrystallized from petroleum ether yielding each of pure 1,1-diacetates. As example, spectroscopic data for the compound $\mathbf{2 b}$ are given:

Compound 2b: White solid: p. f. 80-81 ${ }^{\circ} \mathrm{C}$. IR: 3090, 3016, 2940, 1760, 1753, 1532, 1353, 1218, 1200, 993, 820, 740, $685 \mathrm{~cm}^{-1} .{ }^{1} \mathrm{H}$ NMR $\left(200 \mathrm{MHz}, \mathrm{CDCl}_{3}\right): \delta 7.60(\mathrm{~s}, 1 \mathrm{H}), 7.38(\mathrm{~d}$, $2 \mathrm{H}, \mathrm{J}=8 \mathrm{~Hz}) 7.28(\mathrm{~d}, 2 \mathrm{H}, \mathrm{J}=8 \mathrm{~Hz}), 2.10(\mathrm{~s}, 6 \mathrm{H})$. EIMS: m/z (\%) $242\left(\mathrm{M}^{+}, 2\right), 201(12), 199$ (40), 139 (90), 111 (30), 77 (30) and 43 (100).

\section{Results and Discussion}

The protection reaction is showed in Scheme 1, and it was studied using aldehydes 1a-1s as substrates.

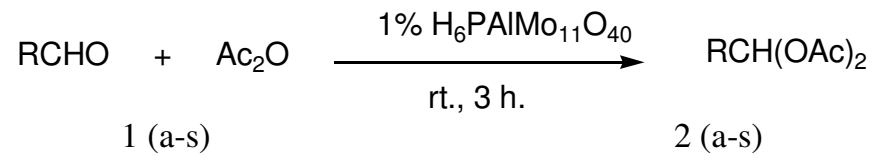

Scheme 1. Preparation of 1,1-diacetates.

The structures of aldehydes, 1,1-diacetates and the obtained results are shown in Table 1.

Benzaldehyde was chosen as the substrate for optimizing the reaction conditions: Temperature, time, concentration of the initial solutions and molar ratio of heteropolyacid to substrate were checked.

Various aldehydes reacted with $\mathrm{Ac}_{2} \mathrm{O}$ to afford the corresponding 1,1-diacetates in high yields. Reaction proceeds smoothly in $3 \mathrm{~h}$ at room temperature $\left(20^{\circ} \mathrm{C}\right)$. Both electronreleasing and electron-withdrawing substituted aromatic aldehydes were converted to their corresponding 1,1-diacetates in the same conditions; the nature of the substituents seems to have no effects on the reaction.

In the case of aliphatic aldehydes, high yields of products are obtained in the mentioned conditions. Acid-sensitive aldehydes, such as crotonaldehyde, furfural and cinnamaldehyde give very good yields, no decomposition or polimerization were observed Hydroxybenzaldehydes afford the corresponding triacetates in excellent yields.

Nevertheless, 4-dimethylaminobenzaldehyde failed to give the expected 1,1-diacetate even the mixture were being stirred for $16 \mathrm{~h}$. We attempted the reaction of acetone, butanone and acetophenone with acetic anhydride; they have not reacted under the described experimental conditions. Besides, acetylation of a mixture of benzaldehyde and acethophenone gave only the 1,1-diacetate from the aldehyde (Scheme 2).

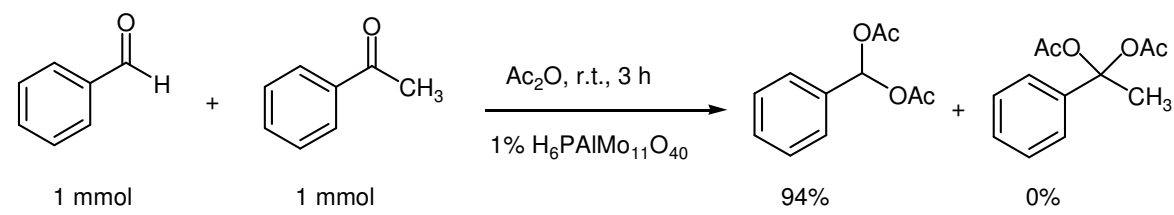

Scheme 2 
Table 1 Preparation of various 1,1-diacetates 2 from the corresponding aldehydes 1 using $\mathrm{H}_{6} \mathrm{PAlMo}_{11} \mathrm{AlO}_{40}$ as catalyst

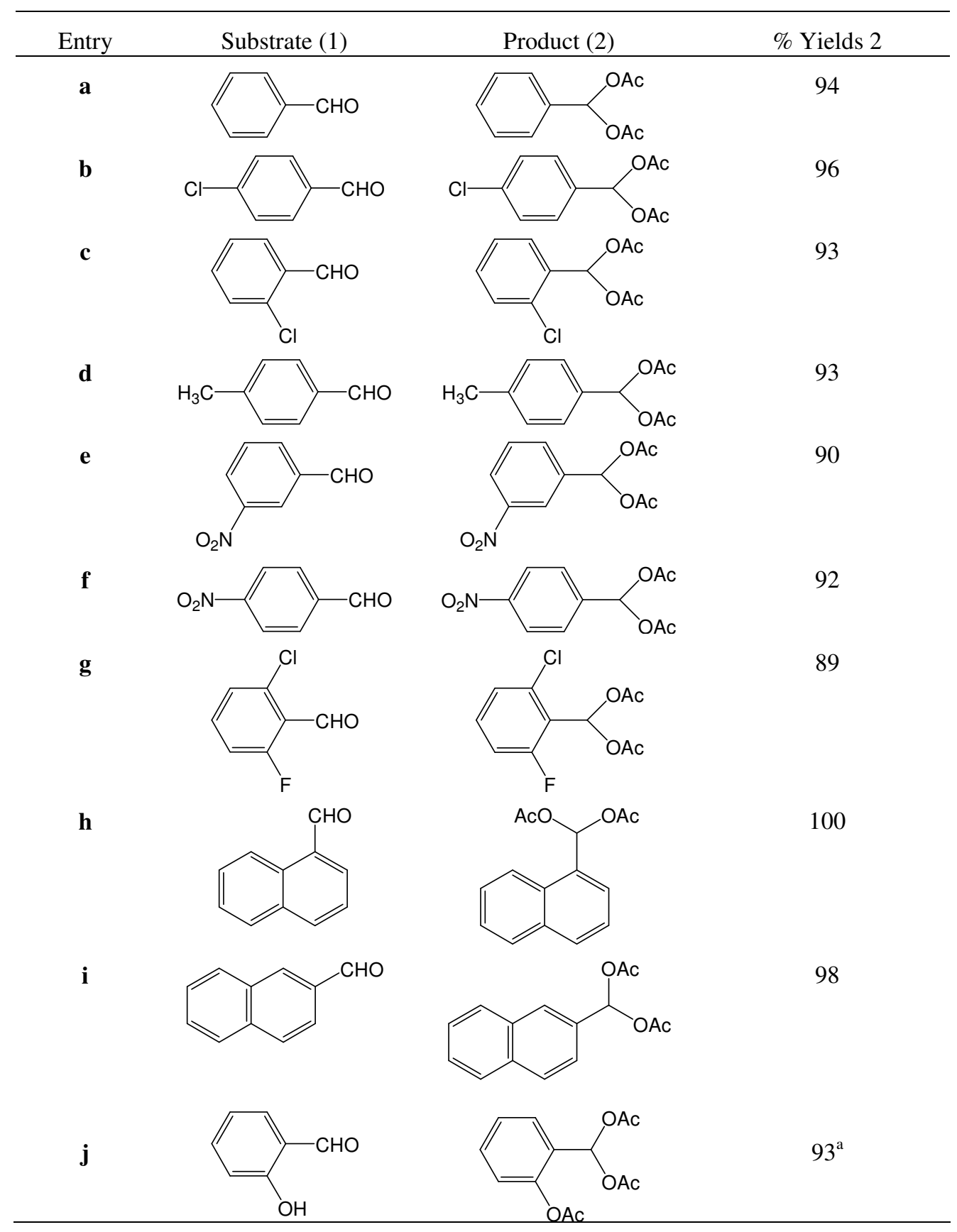

Table 1. Contd... 


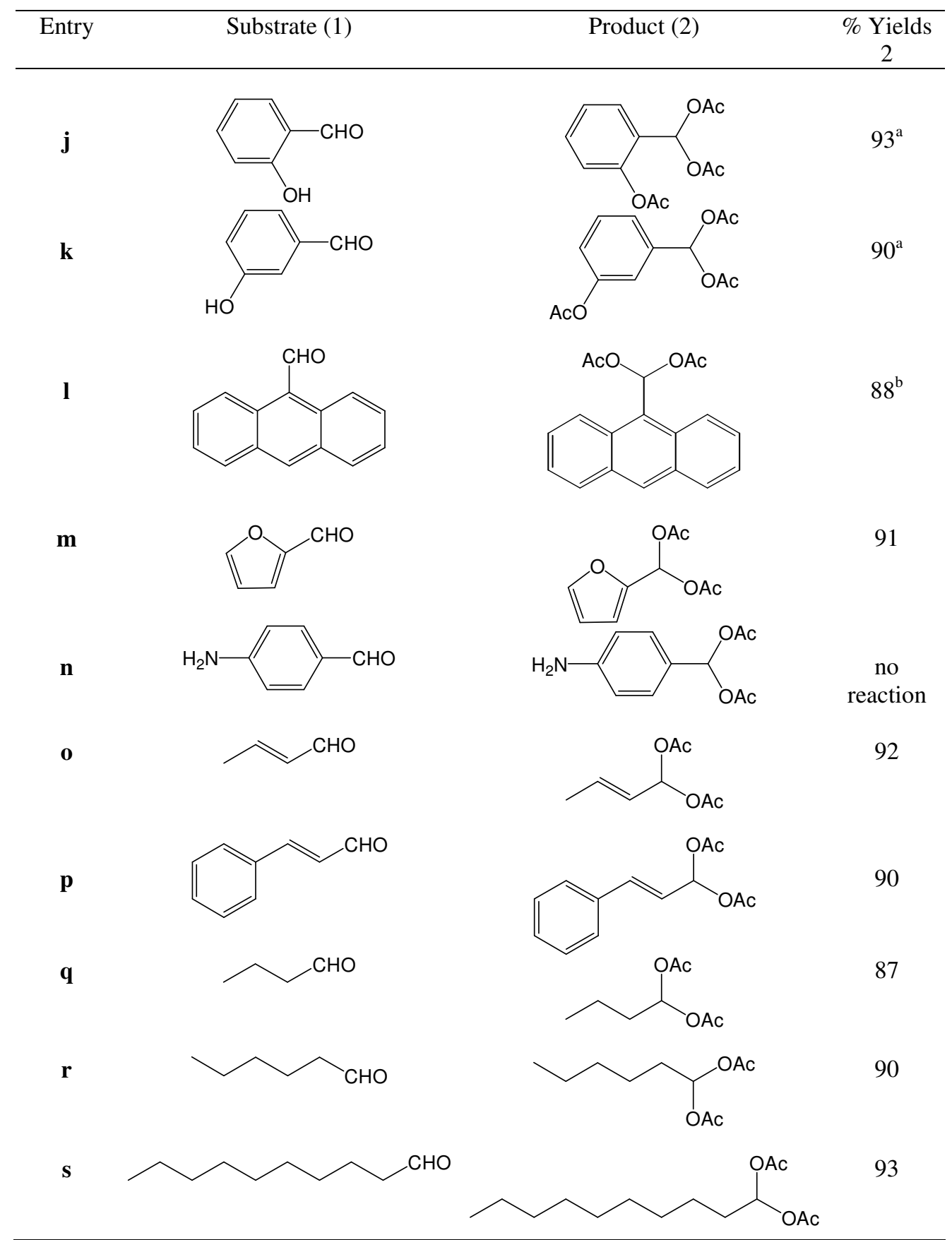

${ }^{\mathrm{a}}$ Compound $2 \mathrm{j}$ y $2 \mathrm{k}$ are the triacetates

${ }^{\mathrm{b}}$ Reaction time was $4 \mathrm{~h}$. 


\section{Conclusion}

We report a new clean, mild and efficient procedure for preparing 1,1-diacetates from aldehydes in the presence of acetic anhydride at room temperature, mediated by a non commercial $\mathrm{H}_{6} \mathrm{PAlMo}_{11} \mathrm{O}_{40}$, a heteropolyacid with Keggin structure, under solvent free conditions. Some advantages of this procedure are the low cost with green methodology, short reaction time and the easy work up.

\section{Acknowledgements}

Financial support from CONICET, Universidad Nacional de La Plata and Fundación Antorchas is gratefully acknowledged. G.P.R and P.G.V. are members of CONICET.

\section{References}

1. Greene T W and Wuts P G M, Protective Groups in Organic Synthesis, John Wiley: New York, 1991.

2. Kumar P, Hedge V R and Kumar T P, Tetrahedron Lett. 1995, 36, 601-602

3. Frick J G and Harper J, J. Appl. Polym. Sci. 1984, 29, 1433-1447.

4. $\quad$ Sandberg M and Sydnes L K, Tetrahedron Lett. 1998, 39, 6361-6364.

5. (a) Lieberman S M and Connor R, Org. Synth. 1951, 2, 441-443; (b) Gregory M J, J. Chem. Soc. B 1970, 1201-1207; (c) Marshall J A and Wuts P G M, J. Org. Chem. 1977, 42, 1794-1798.

6. Kochhar K S, Bal B S, Deshpande R P, Rajadhyaksha S N and Pinnick H W, J. Org. Chem. 1983, 48, 1765-1767.

7. Michie J K and Miller J A, Synthesis 1981, 824-825.

8. Yadav J S, Subba Reddy B V and Srinivas Ch, Synth. Commun. 2002, 32, 1175-1180.

9. Aggarwal V K, Fonquerna S and Vennal G P, Synlett 1988, 849-850.

10. Chandra K L, Saravanan P and Singh V K, Synlett 2000, 359-360.

11. Smitha G and Reddy S Ch, Tetrahedron 2003, 59, 9571-9576.

12. Deka N, Kalita D J, Borah R and Sarma J C, J. Org. Chem. 1997, 62, 1563-1564.

13. Jin T S, Ma Y, Zhang Y Z H and Li T S, Synth. Commun. 1997, 27, 3379-3383.

14. Li T S, Zhang Z H and Gao Y J, Synth. Commun. 1998, 28, 4665-4671.

15. Olah G H and Mehrotra A K, Synthesis 1982, 962-963.

16. Joshi M V and Narasimhan C S, J. Mol. Catal. 1993, 141, 308-310.

17. Li Y Q, Synth. Commun. 2000, 30, 3913-3917.

18. Curini M, Epifanio F, Marcotulio M. C, Rosat O and Nochetti M, Tetrahedron Lett. 2002, 43, 2709-2711.

19. Firouzabadi H, Irampoor N, Nowrouzi F and Amani K, Tetrahedron Lett. 2003, 44, 3951-3954.

20. Kumar R, Thilagavathy R, Gulhane R and Chakraborty A K, J. Mol. Catal. 2006, 226-231.

21. Heravi M, Bakhtiari K and Bamoharram F, Catal. Commun. 2006, 7, 499-501.

22. Zhang Z H, Monatsch. fur Chemie, 2005, 136, 1191-1195.

23. Hajipour A, Zarei A, Khazdooz L, Mirjalili B, Sheikhan N, Zahmatkesh S and Ruoho A, Synthesis, 2005, 20, 3644-3648.

24. Heravi M, Bakhtiari K, Taheri S and Oskooie H, Green Chem, 2005, 7, 867-869.

25. Vázquez P, Pizzio L, Romanelli G, Autino J, Cáceres C and Blanco M, Applied Catal. A: General, 2002, 235, 233-240. 
26. Romanelli G, Vázquez P, Quaranta N, Pizzio L, Autino J, Cáceres C and Blanco M, Applied Catal. A: General, 2004, 261, 163-170.

27. Romanelli G, Baronetti G, Thomas H and Autino J, Tetrahedron Lett. 2002, 43, 75897591.

28. Romanelli G, Bennardi D, Ruiz D, Baronetti G, Thomas H and Autino J, Tetrahedron Lett. 2004, 45, 8935-8939.

29. Romanelli G, Thomas H, Baronetti G and Autino J, Tetrahedron Lett. 2003, 44, 13011303.

30. Dimitroff P, Vázquez P, P. in proceedings of the XIX Simposio Iberoamericano de Catálisis, Mérida, México, 2004, 807-814. 


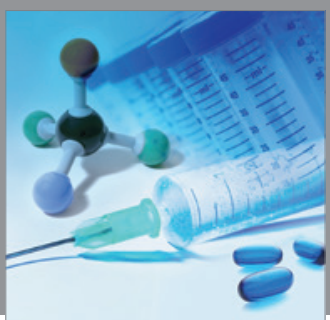

International Journal of

Medicinal Chemistry

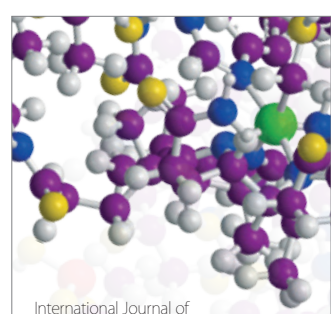

Carbohydrate Chemistry

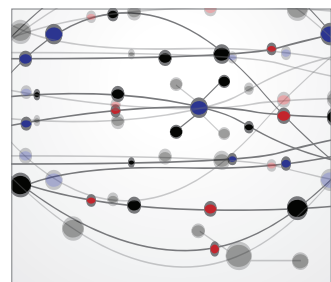

The Scientific World Journal
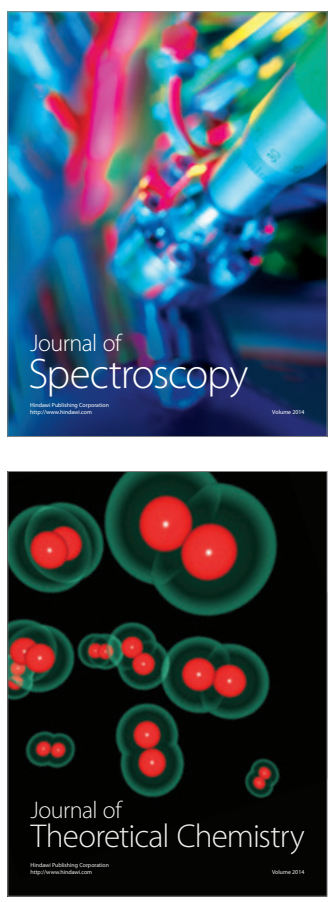
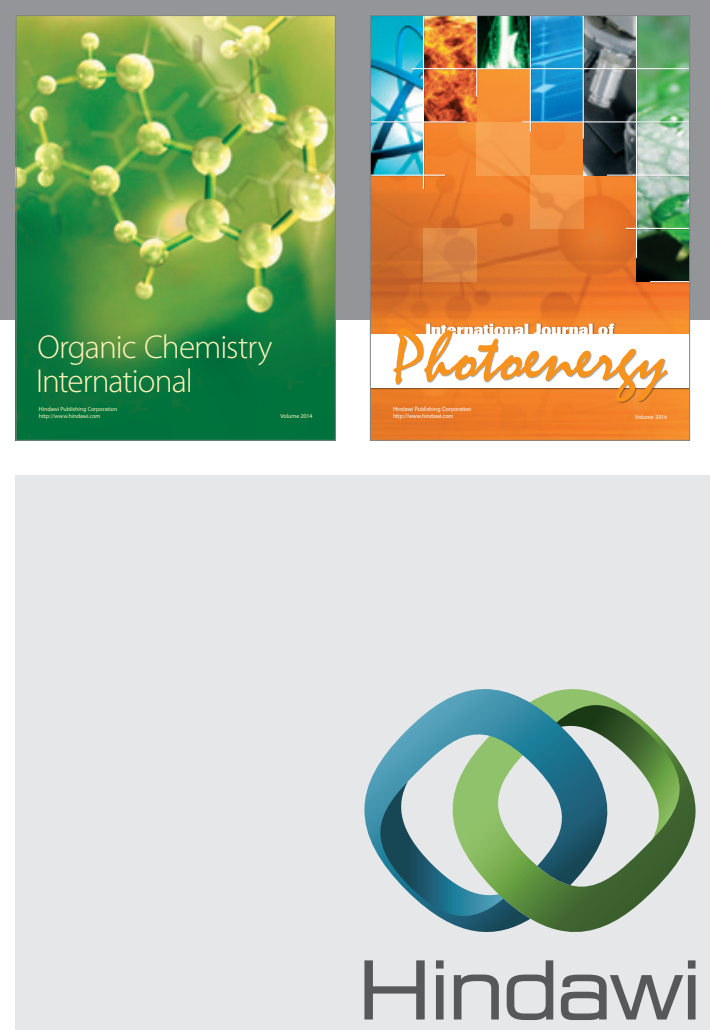

Submit your manuscripts at

http://www.hindawi.com
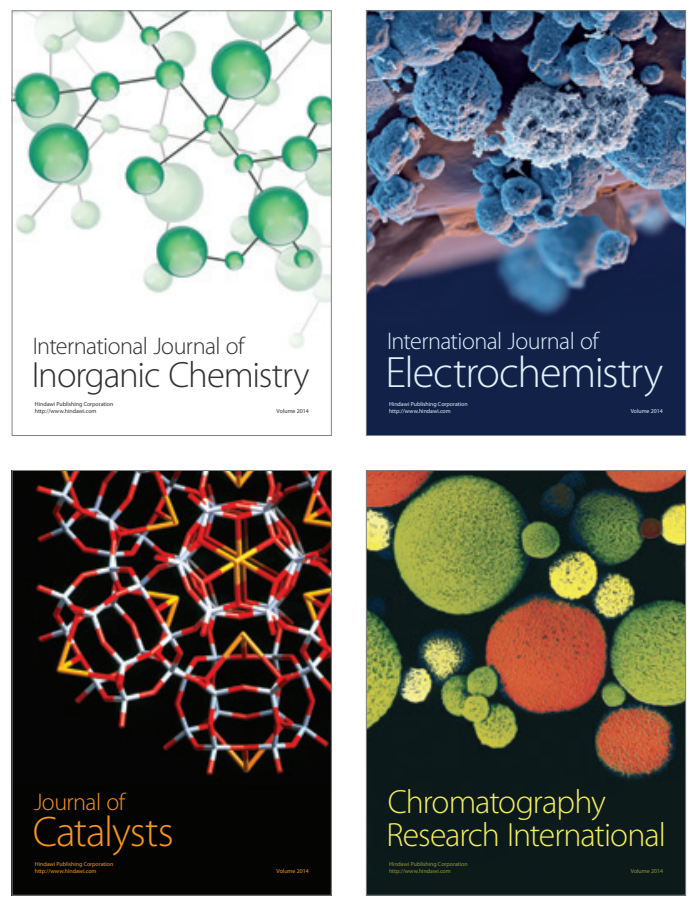
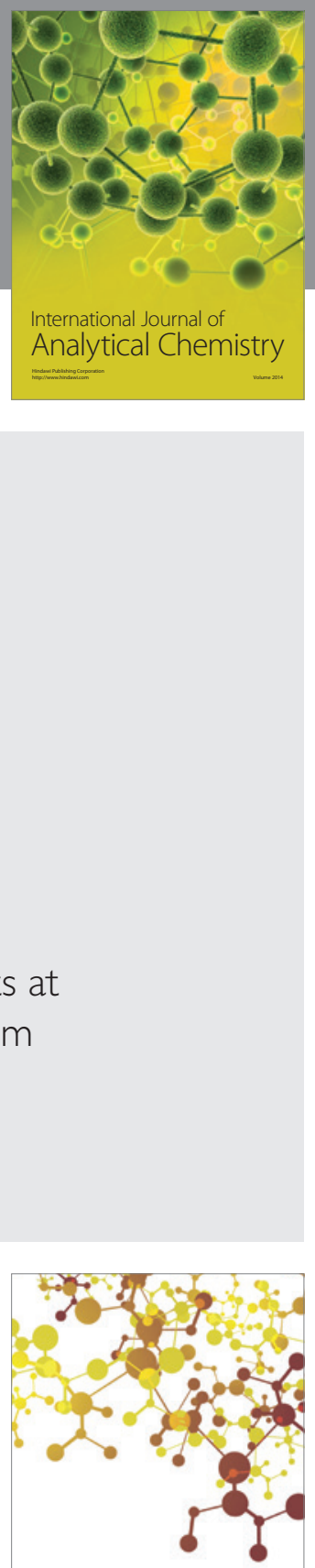

Journal of

Applied Chemistry
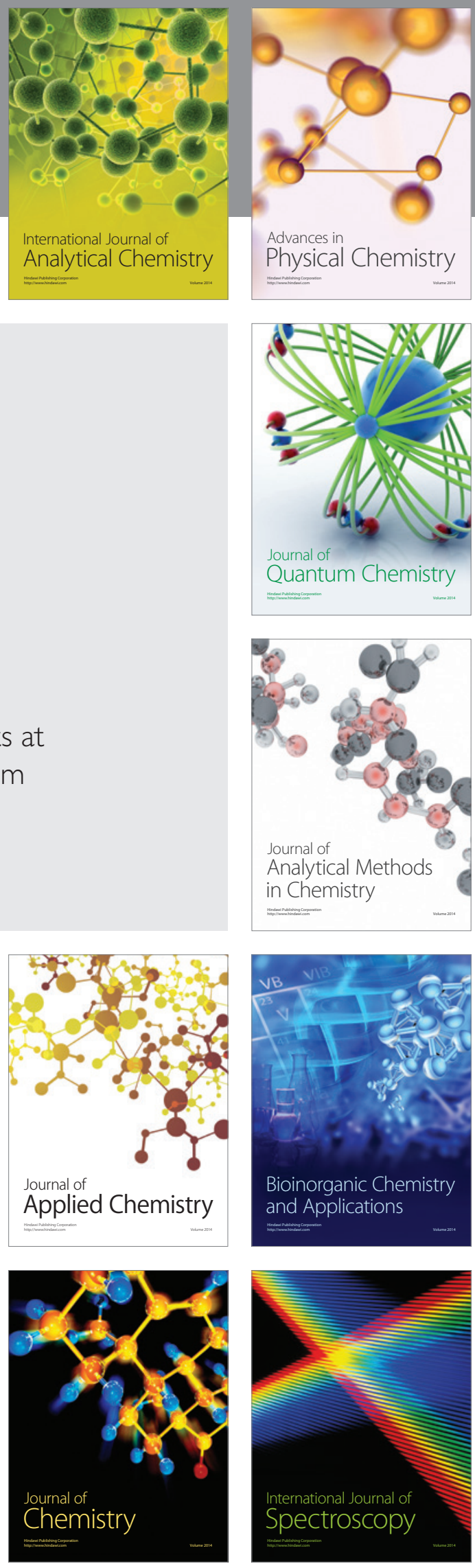